\title{
The Impact of Critical Flutter Velocity in Composite Wind Turbine Blade with Prebend Condition
}

\author{
H. S. Sunil Kumar (D, ${ }^{1}$ K. R. Jagadeesh, ${ }^{2}$ R. B. Anand, ${ }^{3}$ T. Rangaswamy, ${ }^{4}$ Srikanth Salyan, ${ }^{5}$ \\ Jenoris Muthiya Solomon, ${ }^{6}$ Joshuva Arockia Dhanraj $\left(\mathbb{D},{ }^{7}\right.$ \\ and Joshua Stephen Chellakumar Isaac Joshua Ramesh Lalvani ${ }^{8}{ }^{8}$
}

${ }^{1}$ Department of Mechanical Engineering, D.A.C.G. (Govt.) Polytechnic, Chikmagalur 577101, India

${ }^{2}$ Department of Mechanical Engineering, Smt L.V. (Govt.) Polytechnic, Hassan 573201, India

${ }^{3}$ Department of Mechanical Engineering, National Institute of Technology, Tiruchirappalli 620015, India

${ }^{4}$ Departments of Mechanical Engineering, Government Engineering College, Hassan 573201, India

${ }^{5}$ Department of Aeronautical Engineering, Dayananda Sagar College of Engineering, Bangalore 560111, India

${ }^{6}$ Department of Automobile Engineering, Dayananda Sagar College of Engineering, Bangalore 560111, India

${ }^{7}$ Centre for Automation and Robotics (ANRO), Department of Mechanical Engineering,

Hindustan Institute of Technology and Science, Chennai 603103, India

${ }^{8}$ Faculty of Mechanical Engineering, ArbaMinch Institute of Technology, ArbaMinch University, ArbaMinch, Ethiopia

Correspondence should be addressed to H. S. Sunil Kumar; sunil.kumar.slvp@gmail.com

Received 24 November 2021; Revised 6 January 2022; Accepted 28 January 2022; Published 2 March 2022

Academic Editor: Jinyan Song

Copyright (c) 2022 H. S. Sunil Kumar et al. This is an open access article distributed under the Creative Commons Attribution License, which permits unrestricted use, distribution, and reproduction in any medium, provided the original work is properly cited.

\begin{abstract}
The present work focuses on the effect of flutter in prebend $100 \mathrm{~m}$ horizontal axis wind turbine blade (HAWT) within the stability limits. The study was carried out with an advanced beam model for idyllic structure in a DU-97-W-300 cross-sectional area. A Galerkin type of approach has been applied to derive the equations, and the analysis was performed using a standard FEA code which involves the PK method and double lattice method for calculating flutter solution and aerodynamic loads respectively. The results reveal the significance of inducing prebending to improve the stability of the blade structures, and hence, the flutter velocity has moved from $11 \mathrm{~m} / \mathrm{s}$ to $23 \mathrm{~m} / \mathrm{s}$. Furthermore, the output highlights the effect of prebending on the structural stability and also the flutter limit was found to be lengthened.
\end{abstract}

\section{Introduction}

The tremendous increase in energy demand and the factors affecting environmental degradation due to production of energy has resulted in dependence on clean energy resources. Among various resources wind energy has outperformed its counterparts for reliable source for renewable energy resources and vast amount of research and implementation is on rise in the recent decades. The design optimization of wind turbine and blades is essential to extract more energy to meet increasing energy demand which results in study of increasing in blade size while exposing them to high load conditions; at the same time wind blades should be flexible and slender. Because of such slenderness issues there are multiple phenomena which tend to make the blades unstable. Figure 1 and Figure 2 illustrate the wind turbine blade with prebend configuration and prebend blade terminology.

The preliminary sciences of such instabilities like aeroelasticity, flutter instability, and relative factors have been clearly explained in [2]. The structural stability and its mathematical relation with the boundary and load conditions have been derived in [3] while, various types of dynamic instabilities and relations are detailed in [4]. The flutter instability has been found to be capable of becoming a prime design driver for future wind turbine blades and 


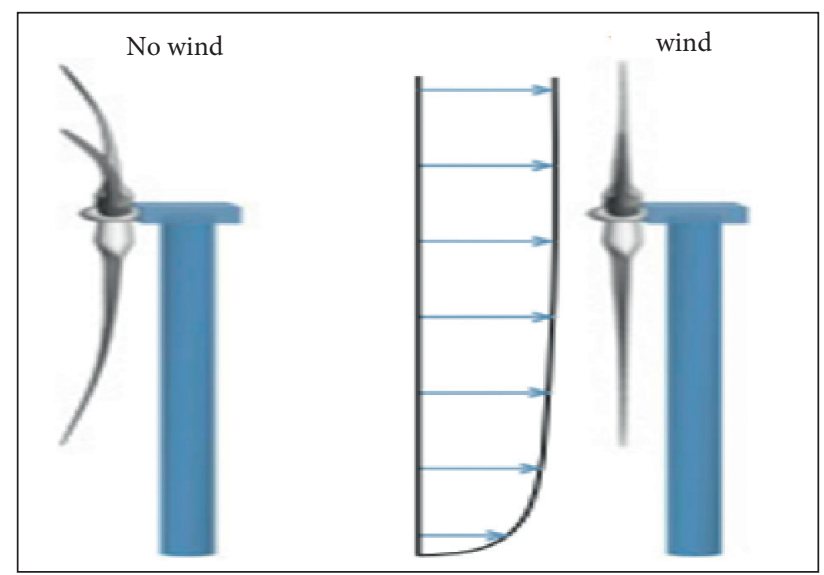

FIgURE 1: Wind turbine blade with prebend configuration [1].

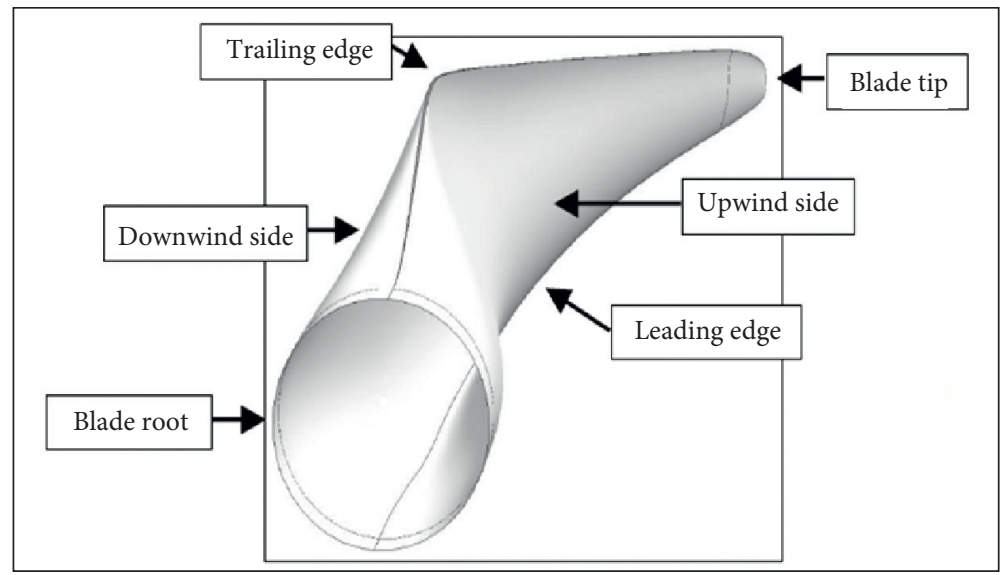

Figure 2: Prebend blade terminology.

thus has emerged as an area of research, where researchers and scientists have come up with several methods to detect, control, and eliminate such instabilities. The flutter instability is considered more important as it is much difficult to detect when compared to resonance. One such method for enhancing the stability is what is called prebending of the blade structure. To tackle such issues without sacrificing the expectations of energy output, prebending of the blade structures is performed to reduce blade weight, improve overall energy generation capacity per annum, and increase tip deflection to a certain extent. The aim of this work is to investigate the wind turbine with prebend condition and its flutter velocity. The preliminary studies investigate the aeroelastic behaviour of blade structures revealing that the flutter limit of a blade depends upon natural frequencies of torsional as well as flapwise direction of a blade [5]. Further, studies on the influence of system parameters and its uncertainties for the wind turbine blades on onset of flutter suggest that structural randomness can make the blade more unstable by decreasing the critical speed for fluttering below the operational speed designated for the wind turbine [6]. After detecting the occurrence of flutter instability, researchers moved further to find optimum methods which show the closeness in approximation using reliability evaluation methods [7]. As further studies kept revealing more and more flutter control parameters, the analysis techniques gained more correctness and reliability [8]. The aeroelastic stability in a wind turbine is presented by another simplified method using Eigen value approach [9] and linear aerostatic turbine model [10] to find the critical frequency of three-bladed rotor arrangements. Similarly, $[11,12]$ study the fluttering of two-dimensional as well as three-dimensional nonlinear cyclic oscillations and its effect on aeroelastic instabilities. An approach to flutter analysis study by nonlinear damping for aerofoil using equivalent linearization [10] and Range Kutta method [13] for various tip speed ratio is reported in literature.

The above analysis investigated the structural instability and flutter analysis of large wind turbine blades; there aroused a necessity to induce structural modification techniques and study their effect on the blade reliability and longer life under the desired operating conditions. Among such modifications, prebending is one where the blade is bent towards aerodynamic pressure to ensure interference margins with the tower. Although this technique has provoked more difficulties in transportation and storage, the studies show that this method has overall impact in the performance and reliability of the structure. Prebending 
being an effective technique has also increased the complexity of design and evaluation as the induced bend has an impact on length of the blade and on angle of attack, thereby affecting the aerodynamic load. Generally, a coupled aerodynamic-structural iterative analysis will predict the aerodynamic loading and structural response in a better way. Paper [14] has conducted a parametric study on a swept blade for a power output of $750 \mathrm{~kW}$ wind turbine along with modification in design conditions. Papers $[15,16]$ investigated the flutter speed for wind turbines with two different types of straight and swept blades. Paper [17] has established several methods for predicting the prebend shape of the wind turbine blades such as when the blades are straightened into their design configuration when they are subjected to both wind and inertial loads. Paper [1] studied the comparison of multiple prebend positions and performed an optimization analysis based on multiobjective particle swarm optimization algorithm (MOPSO) to study the optimized design of blade in order to perform well in reliability, cost, energy efficiency, and stability. The frequency along with deflection change in the geometry with respect to backward sweep is presented in [18]. References [19, 20] made investigations and concluded that backward swept shapes also help in load alleviation without greatly increasing blade root torsion and life-time equivalent fatigue moment. Mehrvarz [21] addressed a Timoshenko beam's asymptotic stability with respect to the effect of piezoelectric actuators. Sahoo [22] compared numerical results computed using MATLAB with experimental data for higher order model of a composite layered shell structure. Meanwhile, Nahavandian [23] investigated the linear stability of thixotropic fluid obeying Moore model using a temporal stability analysis with infinitesimally small perturbations. Fakhraei [24] studied chaotic behaviour of a ground oscillating system by modeling a full nonlinear seven-degree freedom system with an addition of freedom for passengers in one degree. Lobitz [25] studied 3.5 MW turbine blades and concluded that the natural frequencies are subjected to change because of torsional and bending stiffness changes in blades. Meng [26] investigated the flutter frequency as well as critical speed for NREL 5 MW turbine blade for coupling of first torsional and second flapwise modes (instead of the third). Owens et al. [27] developed BLAST, an aerostatic stability design tool, which is an extension of the NASTRAN for flutter analysis for the study with better flutter trends, and studied the impact of composite blade to study the start of instability in blade in two different blades (Wind PACT of 1.5 MW and SNL 100-00 blade). The flutter onset was detected at $13.05 \mathrm{rpm}$ and $40.6 \mathrm{rpm}$ for the SNL 100-00 blades and Wind PACT, respectively. Jonkman et al. [28] developed a design tool called HAWCStab stability tool to study the properties of the blade by using eigenvalue analysis and linearization of nonlinear aeroelastic methods. Shakya et al. [29] observed that flap-torsional stiffness had elevated impact on critical flutter speed which is improved by $40 \%$ due to the unbalance in the complete segment of the blade with symmetric skin. Tamrakar et al. [30] found that the crack had a considerable effect on increasing the natural frequency of the rotor system in contrast to the uncracked rotor system.
This is due to the buildup of the strain energy in the surrounding area of the crack. Yu Hua et al. [31] discussed the analysis of joint state and unknown input evaluation for linear systems with an unknown input and proposed two novel filters as advanced algorithmic control. Further Kai Wang et al. [32] proposed the Kalman filter algorithm for the estimation of state of charge (SOC) in supercapacitors and lithium batteries of electric vehicles. Chunli Liu et al. [33] suggested the new method of estimating the remaining useful life prediction of supercapacitors in energy storage devices. Further the occurrence of flutter instability in delaminated wind turbine blades has been studied [34]. Although these studies have analysed and revealed how prebending of the structure is altering the structural properties and stability, very few studies have been made to understand its influence on flutter limit. But, from these studies, it is clear that prebending seems to have a good impact on the blade's flutter performance. The change of dependency of modes on load conditions has not been studied. This study highlights the change in dependency of a mode on aerodynamic load due to prebending induced on the structure.

\section{Mathematical Modeling}

The equations of motion for a force applied on a body by airflow are dependent on the body's elastic deformation and it obeys both elasticity and aerodynamics theories. Figures 3 and 4 show the flow direction in a blade arrangement and representation of the blade aerofoil DU-97-W-300, respectively. The fluid flows demonstrate the relationship between elastic and aerodynamic parameters. The configuration is supposed to be such that the blade's centre axis is perpendicular to the flow direction and $U$ represents the available free stream air velocity.

A blade can be considered a cantilever beam structure because of its high aspect ratio structure. The current study focuses on the effects of flutter instability, as well as the deformations that result in both torsion and flap directions. The deformation is measured by a deflection ' $\mathrm{X}$ ' and rotation ' $\theta$,' where $\mathrm{X}$ indicates downward displacement and $\theta$ indicates a twist with the leading edge up.

$$
\begin{gathered}
\frac{\partial^{2}}{\partial x^{2}}\left(E I \frac{\partial^{2} X}{\partial x^{2}}\right)+m \frac{\partial^{2} X}{\partial t^{2}}+m y_{\theta} \frac{\partial^{2} \theta}{\partial t^{2}}+F_{L}=0, \\
-\frac{\partial}{\partial x}\left(G J \frac{\partial \theta}{\partial x}\right)+I_{\theta} \frac{\partial^{2} \theta}{\partial t^{2}}+m y_{\theta} \frac{\partial^{2} w}{\partial t^{2}}+F_{M}=0 .
\end{gathered}
$$

Bending and torsional rigidities are represented by EI and GJ, respectively, whereas lift force and twisting moment are represented by $F_{L}$ and $F_{M}$, which are as follows:

$$
\begin{gathered}
F_{L}=\frac{\rho U^{2}}{2} c \mathrm{C}_{1}, \\
F_{M}=\frac{\rho U^{2}}{2} c^{2} \mathrm{C}_{2} .
\end{gathered}
$$




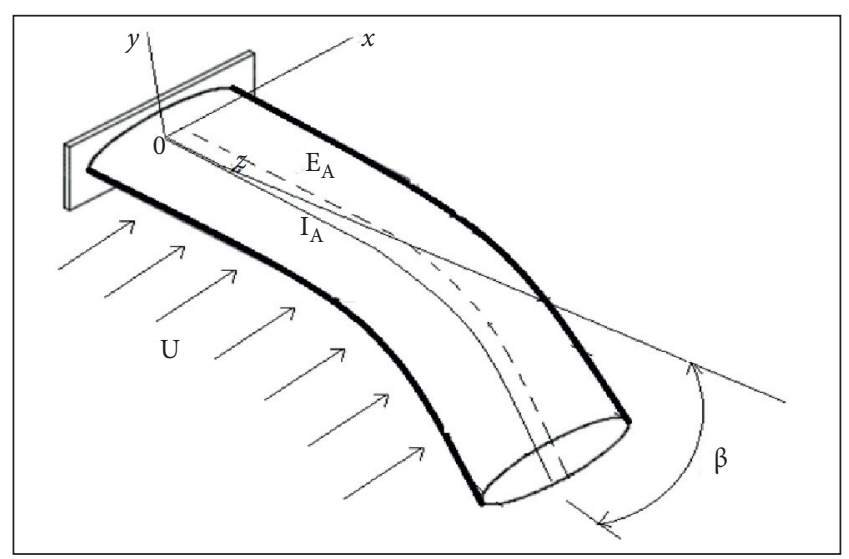

Figure 3: A view of blade arrangement and flow direction.

The lift coefficient $\mathrm{C}_{1}$ and the moment coefficient $\mathrm{C}_{2}$ are calculated using quasi-steady subsonic aerodynamic theory.

$$
\begin{aligned}
& C_{1}=\frac{\mathrm{d} C_{1}}{\mathrm{~d} x}\left(\theta+\frac{1}{U} \frac{\mathrm{d} x}{\mathrm{~d} t}+\frac{1}{U}\left(\frac{3}{4} C-x_{0}\right) \frac{\mathrm{d} \theta}{\mathrm{d} t}\right), \\
& C_{2}=-\frac{c \pi}{8 U} \frac{\mathrm{d} \theta}{\mathrm{d} t}-\frac{1}{4} \mathrm{C}_{1} .
\end{aligned}
$$

The lift force is one-fourth (1/4) of the chord value, as shown in equation (4).

The moment and aerodynamic force of the prebend blade are given by quasi-steady double lattice approach in the aforementioned equations. By using (3) and (4), we get

$$
\begin{aligned}
& \frac{\partial^{2}}{\partial x^{2}}\left(E I \frac{\partial^{2} X}{\partial x^{2}}\right)+m \frac{\partial^{2} X}{\partial t^{2}}+m y_{\theta} \frac{\partial^{2} \theta}{\partial t^{2}}+\frac{\rho U^{2}}{2} c \frac{\mathrm{d} C_{1}}{\mathrm{~d} \theta} \\
& {\left[\theta+\frac{1}{U} \frac{\mathrm{d} X}{\mathrm{~d} t}+\frac{1}{U}\left(\frac{3}{4} c-x_{0}\right) \frac{\mathrm{d} \theta}{\mathrm{d} t}\right]=0} \\
& -\frac{\partial}{\partial x}\left(G J \frac{\partial \theta}{\partial x}\right)+I_{\theta} \frac{\partial^{2} \theta}{\partial t^{2}}+m y_{\theta} \frac{\partial^{2} w}{\partial t^{2}}+\frac{\rho U^{2}}{2} c^{2} \\
& -\frac{c \pi}{8 U} \frac{\mathrm{d} \theta}{\mathrm{d} t}-\frac{1}{4}\left\{\frac{\mathrm{d} C_{1}}{\mathrm{~d} \theta}\left[\theta+\frac{1}{U} \frac{\mathrm{d} X}{\mathrm{~d} t}+\frac{1}{U}\left(\frac{3}{4} c-x_{0}\right) \frac{\mathrm{d} \theta}{\mathrm{d} t}\right]\right\}=0
\end{aligned}
$$

The boundary conditions to be used in the equation for the displacements ' $\theta$ ', ' $\mathrm{X}$ ' are given below:

$$
\begin{gathered}
X=\frac{\partial X}{\partial x}=0 ; \text { for } x \text { values equal to } 0, \\
\frac{\partial^{2} X}{\partial x^{2}}=\frac{\partial^{3} X}{\partial x^{3}}=\frac{\partial \theta}{\partial \mathrm{x}}=0 ; \text { for } x \text { values equal to } L .
\end{gathered}
$$

In the corresponding (5) and (6) the $X, Y$ are considered as two independent equations for the values of $U$ and $y_{\theta}=0$, where $U$ and $y_{\theta}$ represent the aerodynamic and inertial couplings and determined using the following equation:

$$
X(x, t)=A(x) e^{\lambda t} \text { an } d \theta(x, t)=B(x) e^{\lambda t}
$$

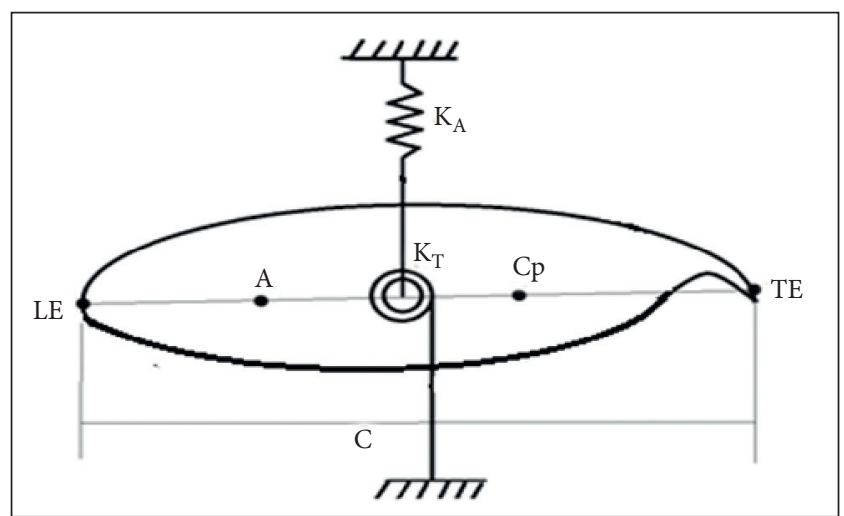

Figure 4: 2D diagram of aerofoil DU-97-W-300.

The ODE equation is obtained by dividing the equation by $e^{\lambda t}$. By applying equation (9) in (5) and (6), we get a complex DE.

$$
\begin{aligned}
& \left(\mathrm{EIA}^{\prime \prime}\right)^{\prime \prime}+\frac{\rho U^{2}}{2} c \frac{\mathrm{d} C_{1}}{\mathrm{~d} \theta} B+\lambda \frac{\rho U}{2} c \frac{\mathrm{d} C_{1}}{\mathrm{~d} \theta}\left[A+c\left(\frac{3}{4}-\frac{y_{\theta}}{c}\right) B\right] \\
& +\lambda^{2} m\left(A+y_{\theta} B\right)=0 \\
& -(\mathrm{GJB})-\frac{\rho U^{2}}{2} c^{2}\left(\frac{y_{\theta}}{c}-\frac{1}{4}\right) \frac{\mathrm{d} C_{1}}{\mathrm{~d} \theta} B-\lambda \frac{\rho U}{2} c^{2} \\
& +\left\{\left(\frac{y_{\theta}}{c}-\frac{1}{4}\right) \frac{\mathrm{d} C_{1}}{\mathrm{~d} \theta} A+c\left[\left(\frac{y_{\theta}}{c}-\frac{1}{4}\right)\left(\frac{3}{4}-\frac{y_{\theta}}{c}\right) \frac{\mathrm{d} C_{1}}{\mathrm{~d} \theta}-\frac{\pi}{8}\right] B\right\} \\
& +\lambda^{2}\left(m y_{\theta} A+I_{\theta} B\right)=0,
\end{aligned}
$$

where ()$^{\prime}=\mathrm{d} / \mathrm{d} x$ and ()$^{\prime \prime}=\mathrm{d}^{2} / \mathrm{d} x^{2}$

The boundary conditions are applied and remain the same as before, except the values $X$ and $\theta$, which are replaced by $A$ and $B$. The partial derivatives of $X$ are replaced by total derivatives. Since there is no way to solve (9) and (10) in closed form, an approximate answer is used in the study. The impact of airflow velocity $U$ on wind blade is examined by eigenvalue which determines the structure's stability condition. The parameter $(\lambda)$ depends upon the air velocity $U$ in a continuous form. For the nonzero values of $U$, a small value takes an exponent value and becomes a complex value $\lambda=\alpha+i_{\omega}$. This value is examined using non-self-nearby (adjoint) values. For values which are not equal to zero but are very small, both the $\mathrm{U}$ and $\left(\mathrm{dC}_{1} / \mathrm{d} \theta\right)$ with a condition of less than $<2 \pi$, the losses of blade are more with most of the energy being lost to the surrounding air. This causes the oscillatory motion to be damped and instability exhibiting asymptotically for which ' $\alpha$ ' takes negative value.

As the value of $U$ rises, " $\alpha$ " changes from negative to positive, and the " $\alpha$ " sign changes and becomes unstable at a point where $\alpha$ becomes positive. Also, when the critical velocity $\alpha=0$ is the air velocity, that corresponds to 0 and is represented by Uc. There critical velocity values for $U$ have numerous different values; however the lowest value for critical velocity value is used to determine the limit or operational range. The value of $U$ can be used to distinguish between two critical circumstances. The critical divergent 


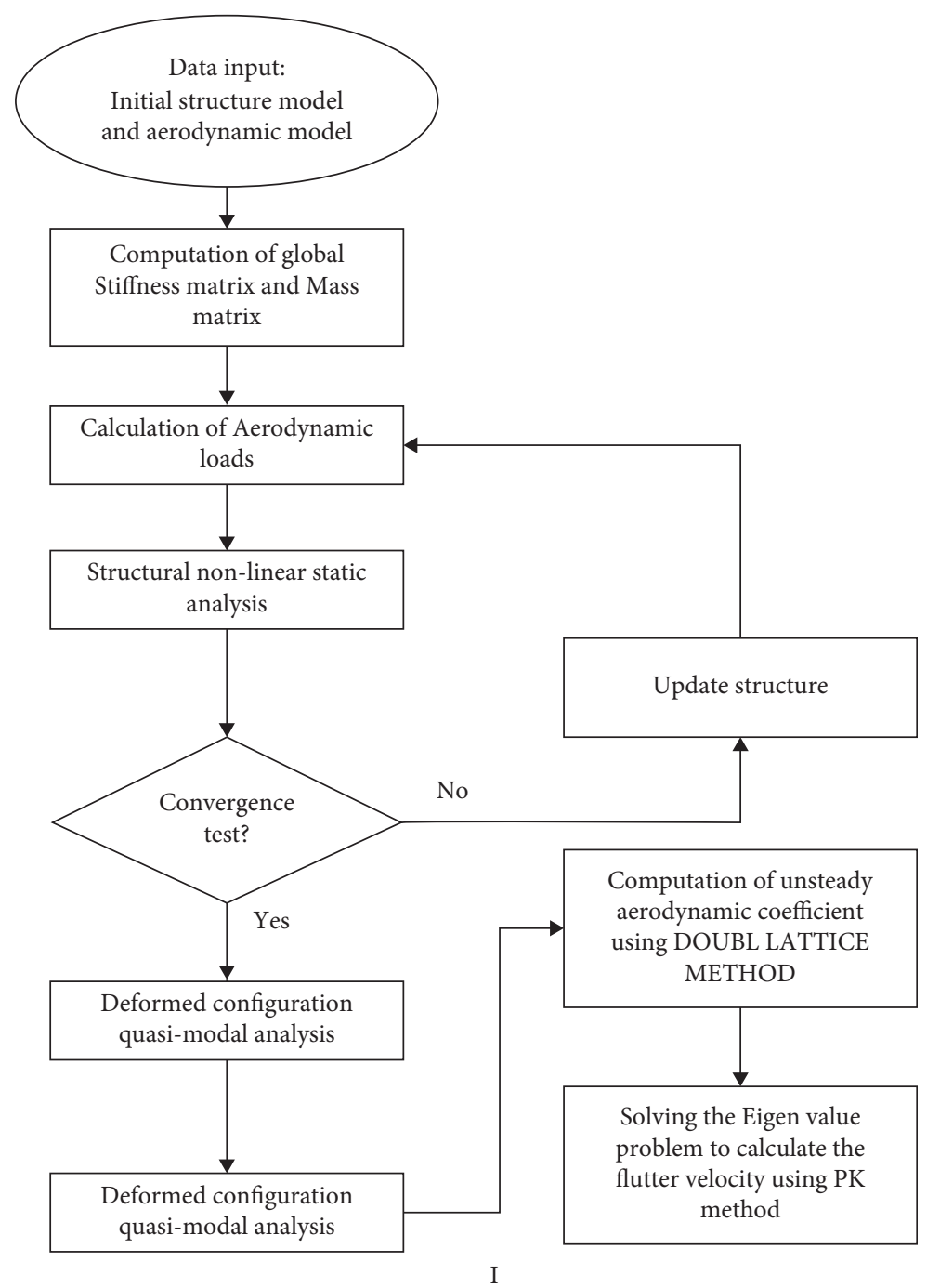

FIgURE 5: Flow process of the analysis.

TABle 1: Ply stiffness properties.

\begin{tabular}{|c|c|c|c|c|c|}
\hline Material & $E_{\mathrm{xy}}(\mathrm{GPa})$ & $E_{\mathrm{yy}}(\mathrm{GPa})$ & $G_{x y}(\mathrm{GPa})$ & $v x y$ & Density $\left(\mathrm{kg} / \mathrm{m}^{3}\right)$ \\
\hline Gel coat & 3.44 & 3.44 & 1.38 & 0.3 & 1235 \\
\hline Resin & 3.5 & 3.5 & 1.4 & 0.3 & 1100 \\
\hline Foam & 0.256 & 0.256 & 0.022 & 0.3 & 200 \\
\hline TRIAX & 27.7 & 13.65 & 7.2 & 0.39 & 1850 \\
\hline E-LT-5500 & 41.8 & 14.0 & 2.63 & 0.28 & 1920 \\
\hline Saertax & 13.6 & 13.3 & 11.8 & 0.51 & 1780 \\
\hline
\end{tabular}

TABLe 2: Flutter speed comparison.

\begin{tabular}{lccc}
\hline References & Blade & Blade length $(\mathrm{m})$ & Critical flutter speed (rpm) \\
\hline Lobitz [25] & WindPACT 1.5 MW & 33 & 42.3 \\
Hansen [9] & NREL 5 MW & 63 & 24.0 \\
Owens and Griffith [27] & SNL 100 & 100 & 13.05 \\
Current study & SNL 100 & 100 & 14.12 \\
\hline
\end{tabular}


TABle 3: Mode frequency comparison.

\begin{tabular}{lccccc}
\hline Frequency & Meng [26] & Jonkman et al. [28] & Paryaya et al. [5] & Hansen et al. [9] & Present study \\
\hline 1st flapwise & 0.72 & 0.7 & 0.64 & 0.7 & 1.8 \\
2nd flapwise & 2.05 & 2.02 & 1.86 & 3.6 & 0.6 \\
3rd flapwise & 4.37 & - & 4.34 & 8.75 \\
1st torsional & 5.62 & - & 5.39 & 8.49 \\
\hline
\end{tabular}

TABLE 4: Natural frequency of prebend and flat modes.

\begin{tabular}{lcc}
\hline Mode & Prebend blade mode frequency $(\mathrm{Hz})$ & Flat blade mode frequency $(\mathrm{Hz})$ \\
\hline 1st bending mode & 0.28 & 0.26 \\
1st torsion mode & 0.52 & 0.45 \\
2nd bending mode & 0.99 & 0.90 \\
3rd bending mode & 2.21 & 1.94 \\
4th bending mode & 2.24 & 2.03 \\
2nd torsion mode & 4.07 & 3.68 \\
1st chordwise bending mode & 4.91 & 4.66 \\
3rd torsion mode & 5.61 & 5.24 \\
4th torsion mode & 6.46 & 5.87 \\
2nd chordwise bending mode & 9.23 & 8.38 \\
\hline
\end{tabular}

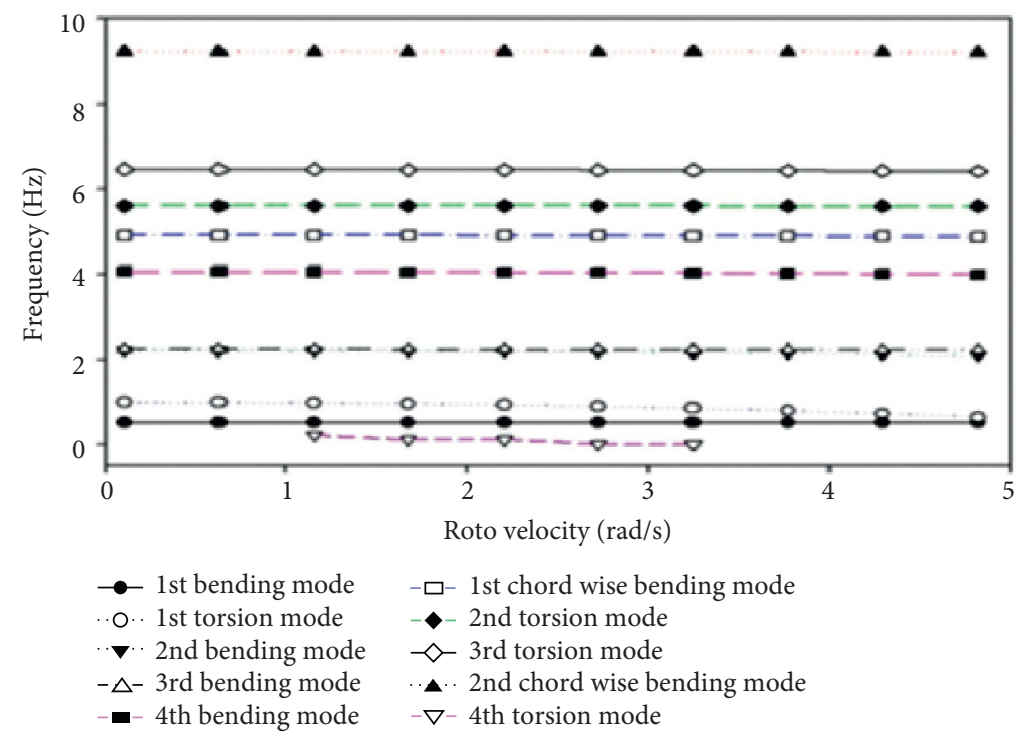

Figure 6: Eigen frequencies for the blade with respect to rotor velocity.

state is given by the values for $\alpha=0$ and $\omega=0$ for the wing and critical flutter condition for blade is given for the conditions of $\alpha=0$ and $\omega \neq 0$.

\section{Methodology}

The Galerkin approach is used to solve the coupled partial differential equations of motion, which discretizes the equations spatially and provides an analysis of flexible structural instabilities owing to fluid flow.

The torsional and flapwise displacements using Galerkin approach are given by

$$
\begin{aligned}
& A=\sum_{j=1}^{n} \varphi_{1}(x) \cdot q_{1}(t), \\
& B=\sum_{j=n+1}^{n^{\prime}} \varphi_{2}(x) \cdot q_{2}(t) .
\end{aligned}
$$

In this equation, $\varphi_{1}$ and $\varphi_{2}$ represent the torsion and flap wise mode whereas $n$ and $n^{1}$ represent the mode numbers in both torsional and flapwise directions. Similarly, $q_{1}, q_{2}$ are synchronized with respect to the directions. The nondimensional lift and moment equations are substituted in the equation and multiplied by the values of Eigen values. The values are integrated with 


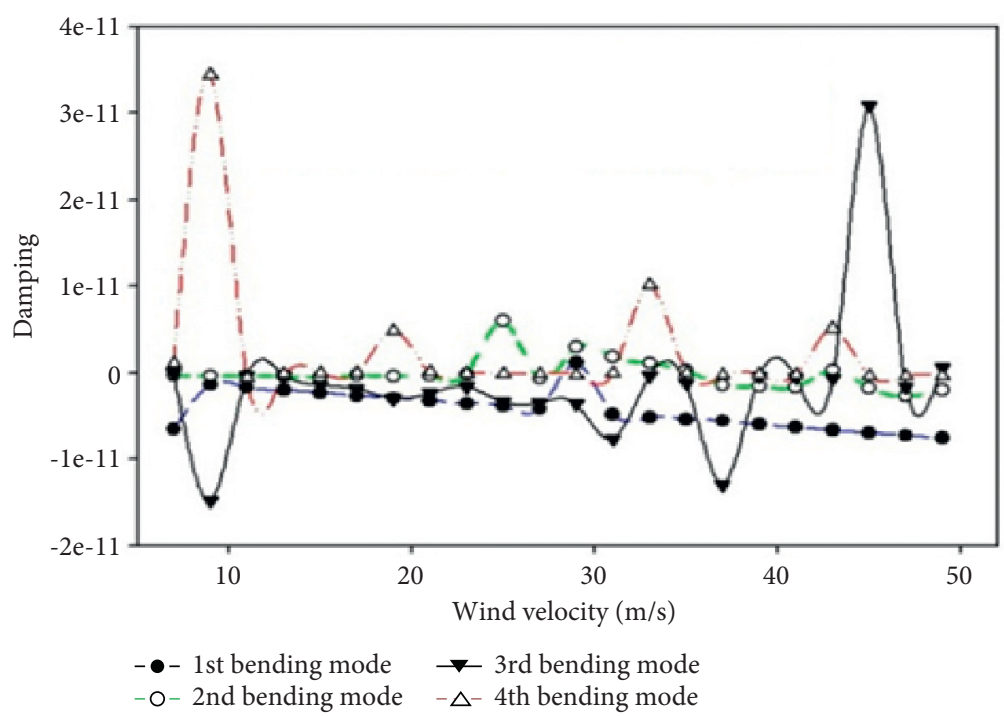

FIGURE 7: Damping curves of the blade bending modes with respect to the wind velocity.

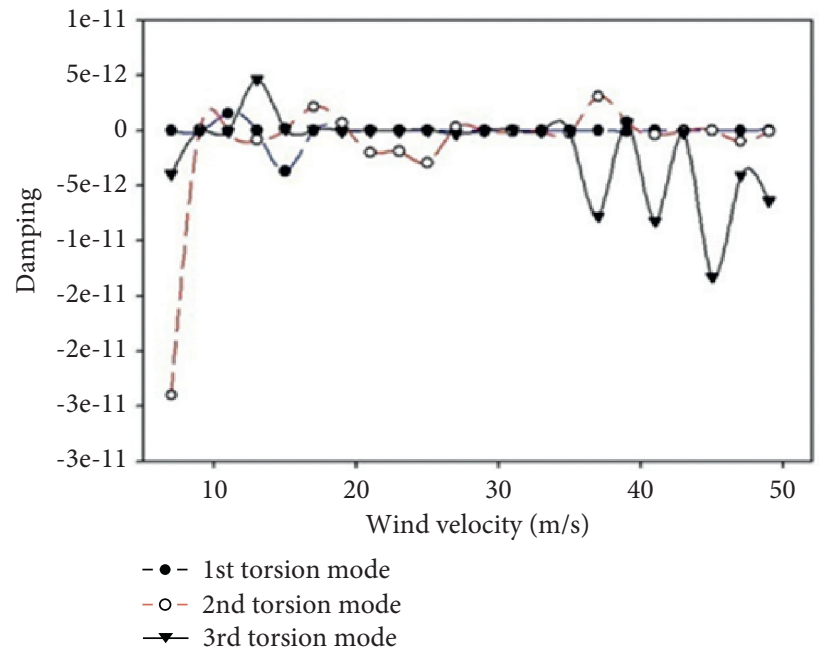

FIGURE 8: Damping curves in blade torsion modes with respect to the wind velocity.

respect to the length of the blade. The obtained equation corresponds to the eigenvalue problem, solving which gives the stability analysis of the blade structure. Figure 5 explains the computation of unsteady aerodynamic coefficient using double lattice method and solving the eigenvalue problem to calculate the flutter velocity using PK method.

The eigenvalue problem equation upon integration for the values of 0 to $L$, for the length of the blade,

$$
\left[[K]+U^{2}[Q]+\lambda^{2}[M]\right] a=0 .
$$

The equation is solved for the increased values of $U$ to solve the value of $U_{\mathrm{c}}$. The $\lambda$ value will be negative for the small values of $U$ and it is approximately equal to 0 for the first value of the critical air speed $U_{c}$. On approximating $A$ and $B$, Uc values are obtained for the values of $n$ and $m$ equal to 1 . For the values of $\lambda=i_{\omega}$, Uc will be equal to $U$, which gives an equation in the form of determinant.

$$
\left[\begin{array}{cccc}
i \omega & 0 & -1 & 0 \\
0 & i \omega & 0 & -1 \\
k_{11} & U^{2} h_{12} & i \omega m_{11}+U l_{11} & i \omega m_{12}+U l_{12} \\
0 & k_{22}+U^{2} h_{22} & i \omega m_{12}+U l_{21} & i \omega m_{22}+U l_{22}
\end{array}\right]=0 .
$$

By substituting into the real part of (13), we can write the quadratic equation in $U^{2}$ as 


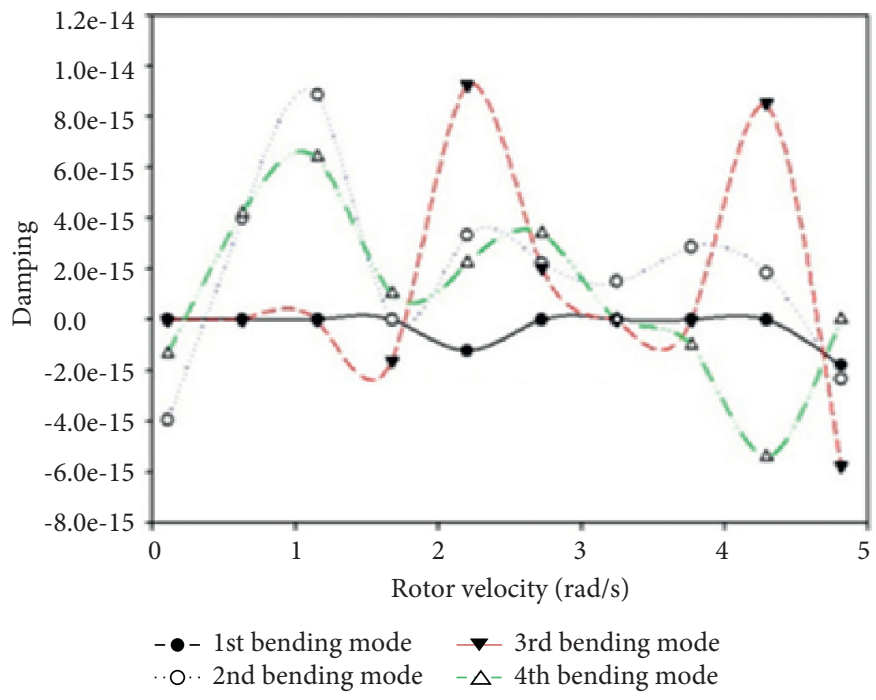

Figure 9: Damping curves of blade bending modes with respect to rotor velocity.

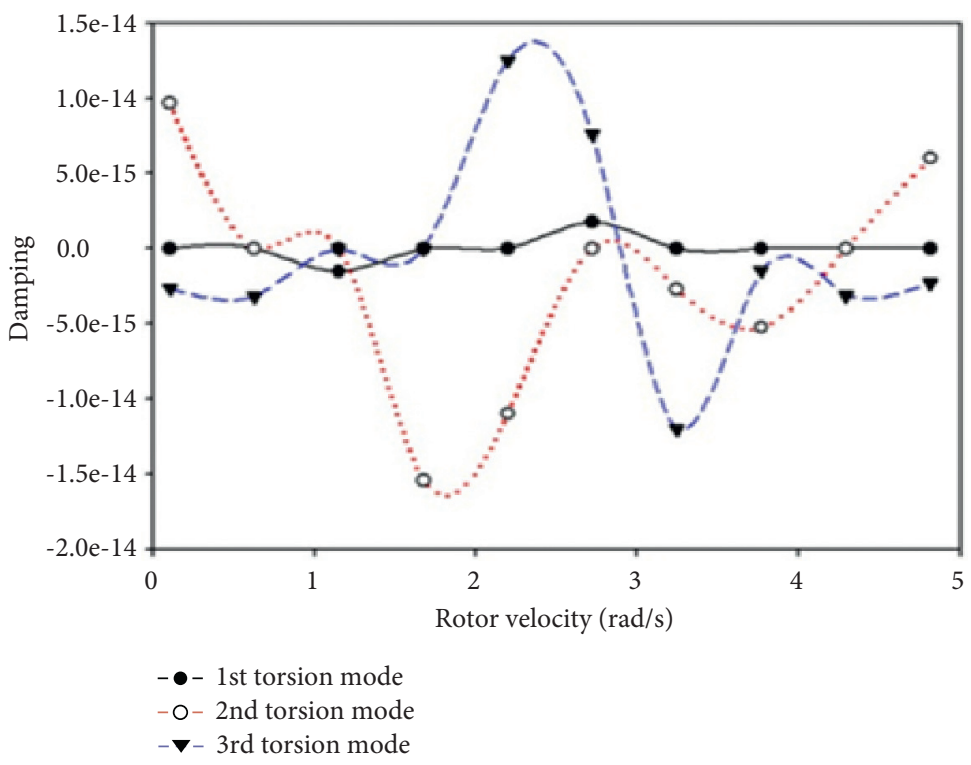

FIGURE 10: Damping curves of blade torsion modes with respect to rotor velocity.

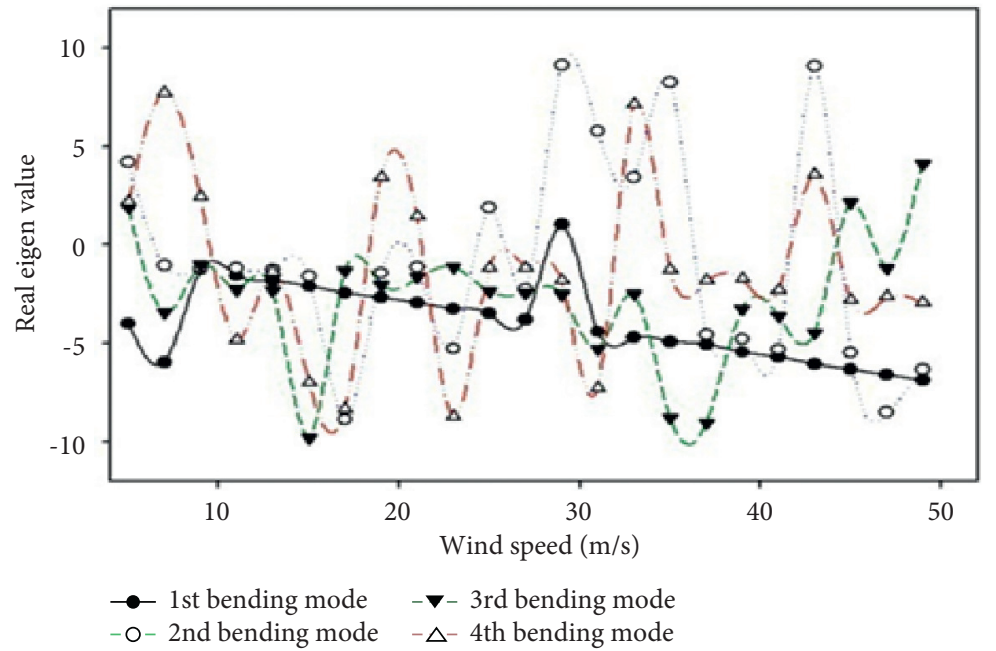

FIGURE 11: Impact of wind velocity for real eigenvalue in bending modes. 


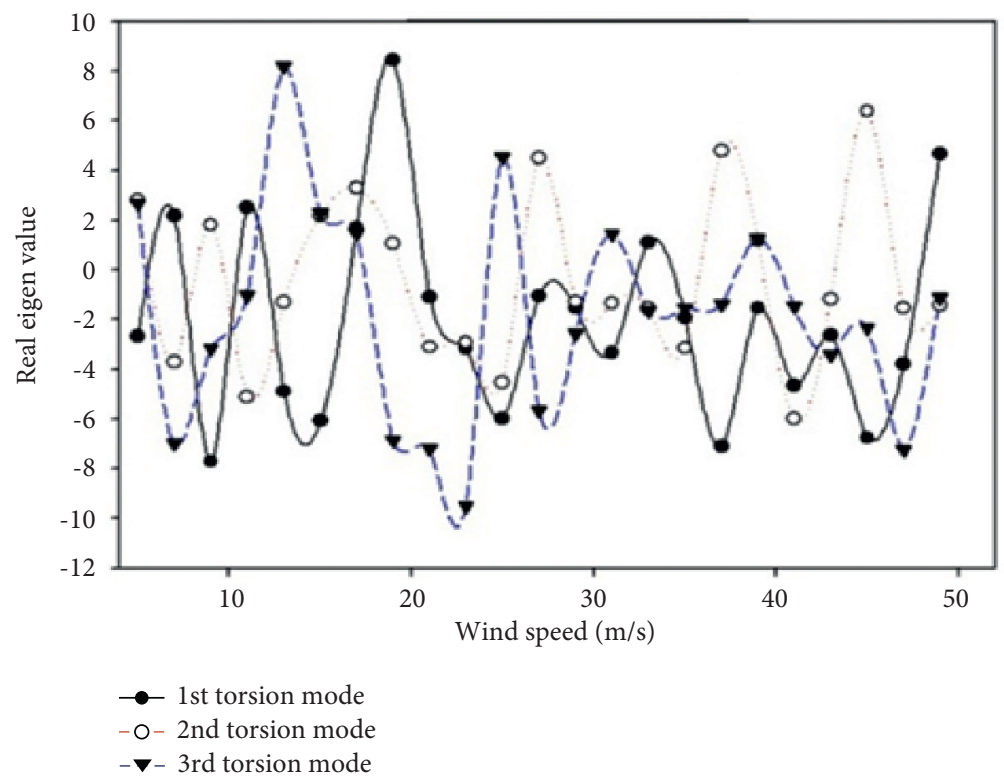

FIGURE 12: Impact of wind velocity in torsion modes.

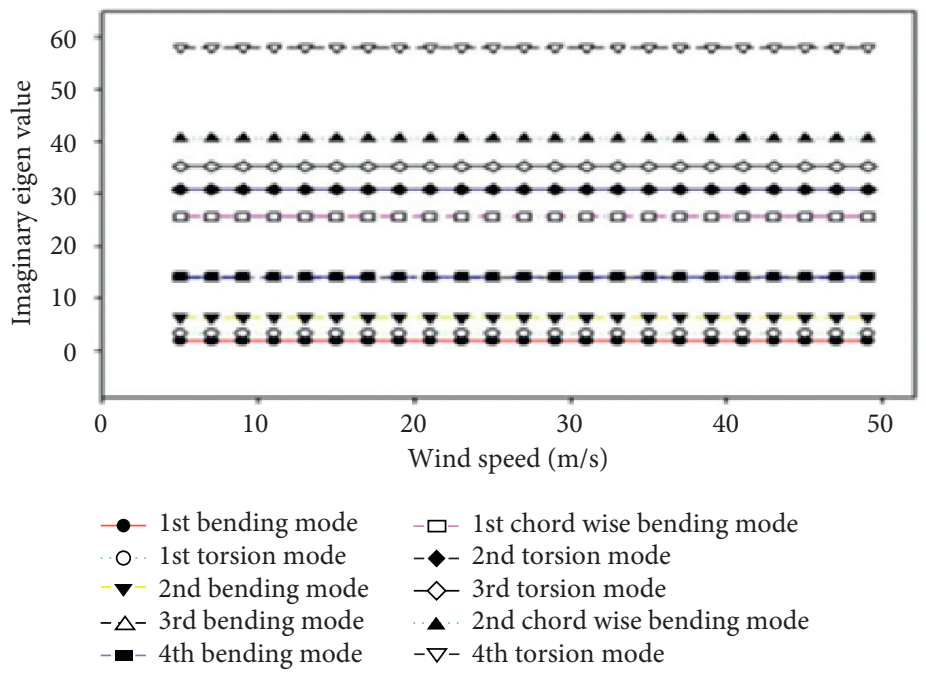

FIGURE 13: Imaginary part of the eigenvalue with respect to wind velocity.

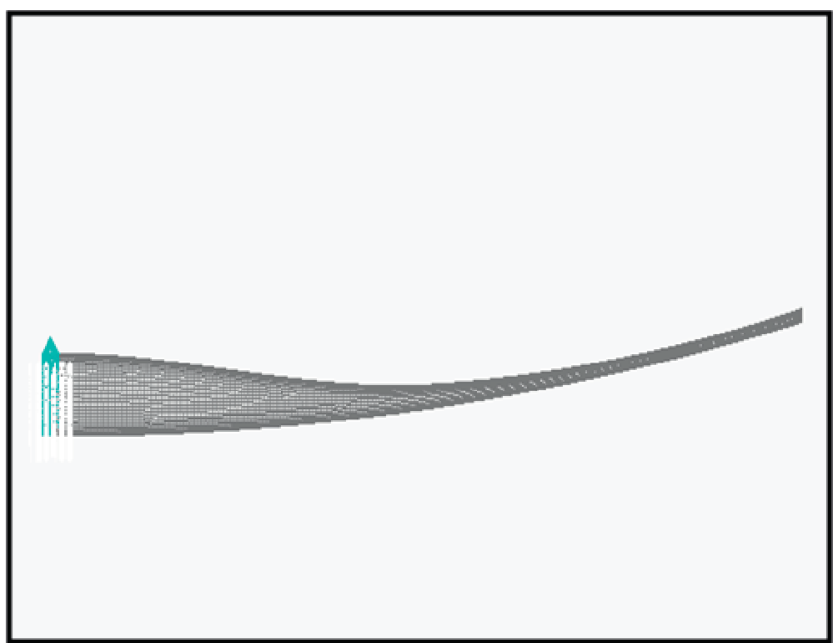

Figure 14: Prebend blade with initial tip deflection. 


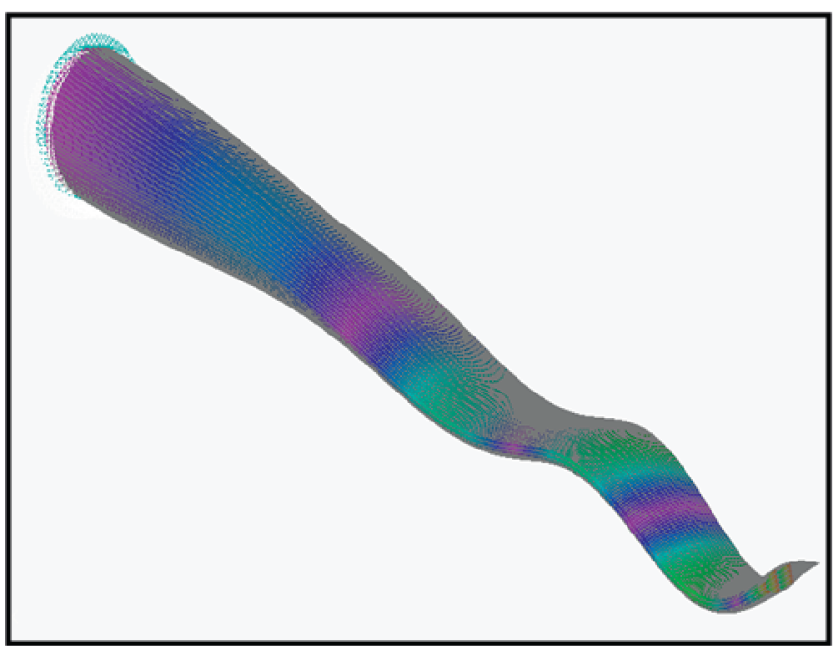

FIGURE 15: Bending mode of the prebend blade.

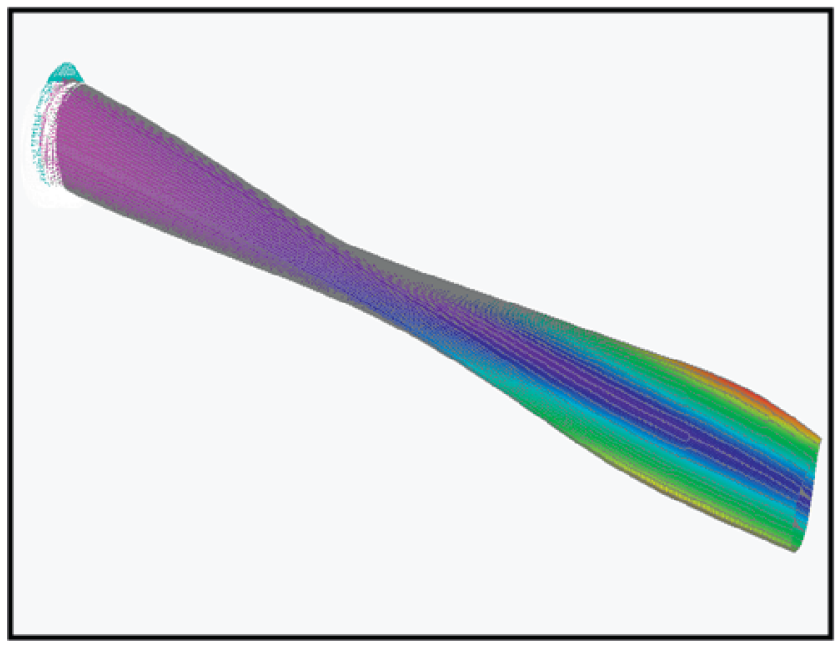

FIGURE 16: Torsion mode of the prebend blade.

$$
C U^{4}+D U^{2}+F=0 .
$$

On substituting the values in (13),

$$
U^{2}=-\frac{D}{2 C} \pm \frac{1}{2 C} \sqrt{D^{2}-4 C F}
$$

The iterations are carried out for a number of $U$ values, with the air speed with the least positive value taken as critical air speed for which the structural stability exists for the values below this critical air speed. The critical air speed is represented by $U_{C}$ and is compared to that with prebend and flat blade to study the impact of flutter limit analysis in a wind turbine blade.

3.1. Estimation of Onset for the Flutter Instability. The predication of flutter limits in wind turbine blades is carried out by time dependent aeroelastic analysis or eigenvalue analysis. The eigenvalue analysis involves a model of steady state equilibrium, which is a linear model for blade. This eigenvalue problem is used to study the instability mechanisms. Standard FEA blade model code is used for different blade arrangements and its properties are given in Table 1. The 100-meter blade is used in this study with the boundary conditions applied as stated in (6) and (7), where the blade behaves similar to the cantilever beam. A $5 \mathrm{~m}$ tip deflection and an initial bend are also included in the structure. At an altitude of 121.92 meters, the airspeed is gradually increased from $0 \mathrm{~m} / \mathrm{s}$ to $50 \mathrm{~m} / \mathrm{s}$, where the air density corresponds to replicating the blade's surrounding conditions. The blade DOF is depicted in 2D diagram (Figure 4). The mathematical model is solved by $\mathrm{PK}$ method for flutter analysis and validates equation by developing aerodynamic matrices for variables such as air speed and frequency. The blade model imported into the standard FEA code is assigned with the composite layup arrangement whose characteristics are listed in Table 1. 
3.2. Parametric Study. Now, the parameters like aerodynamic load are varied by varying the wind speed and from its output, the damping curves for the prebend structure are presented with the help of Campbell diagram. Two graphs are obtained for damping ratio due to dynamic as well as inertial forces acting due to the speed of the rotor and change in wind velocity. Also, the comparison shows the influence of aerodynamic load and inertial forces on the modes can be understood. Similarly, the change in stability of the blade due to prebending can also be observed. And also, the flutter speed comparisons with previous research and present one have been shown in Table 2 and further mode frequency comparisons have been tabulated in Table 3.

\section{Results and Discussion}

The modes of the prebending are studied for natural frequencies and analysed with the same flat blade parameters. The frequency of all the modes in the study is in proximity to each other and thereby the prediction behaviour can be inferred due to the participation of all modes in flutter analysis of the blade structure. Table 4 compares the modal analysis output obtained for flat and prebend configuration of the blade structure.

The results are plot showing the Eigen frequencies with respect to the increasing rotor velocity of blade; in Figure 6, it is observed that the rotor velocity has a significant influence among 1st, 2nd, and 3rd bending mode and 1st torsional mode. Thus, this Campbell diagram can act as evidence to predict the modes that would contribute in the flutter analysis of the blade.

From Figure 7, the damping curve for bending modes is nonlinear and indicates the stability of the bending modes when the wind velocity is increased. The $3 \mathrm{rd}$ and 4 th bending modes show a higher sensitivity to the wind velocity changes than the 1st and 2nd bending mode.

Figure 8 shows the damping curves with respect to wind velocity. It is also noted that 1 st and 2 nd torsion mode are capable of easily initiating instability as their curves lay close to zero throughout the graph. But the 1st torsion mode seems to be more stable while the 2nd mode is not as stable as the first one. The graph also indicates the dominance of the 2nd torsion mode when it comes to contributing to the flutter mode as change in dampening ratio shows the sign change in the flutter velocity.

The graph in Figure 9 with curves plotted for damping with respect to rotor velocity clearly depicts the drastic change in slope of all bending modes, where 1st bending mode shows exception for a critical rotor speed in the range between 20 and $30 \mathrm{rpm}$. The $3 \mathrm{rd}$ and 4 th bending mode show a mild and sensitive variation with respect to the rotor velocity. The more stable conditions are obtained for low rotor velocities and it can be concluded that, with changing the design to improve the flutter limit, more ideal rotor speed is the velocity of less than $20 \mathrm{rpm}$ for aerodynamic properties with an onset of flutter stability.

Figure 10 shows the damping curves variation along the rotor velocity. The graph shows that the 1st torsion mode is quite stable compared to the other torsion modes.
Meanwhile, torsion modes 2 and 3 are found to be highly sensitive and nonlinear to rotor velocity.

Figures 11 and 12 reveal real part of eigenvalue for the bending and torsion modes and the plot is in acceptance with the inference gained from the damping ratio plots.

Figures 13 and 14 of flutter analysis show recorded behaviour of flap and torsional modes with the onset of flutter in the prebend blade.

In Figures 15 and 16, the initial tip deflection and simultaneous bending and torsion contribution of bending and torsion mode are clearly observed. It can be inferred that the deformation of blades is both flapwise and torsional revealing the excitation in both modes under the same frequency, and structure dampening capacity is exceeded due to the higher absorbed energy.

\section{Conclusion}

The investigation was carried out with a focus to detect the occurrence of flutter instability in a horizontal axis large wind turbine blade with prebend (HAWT). The literature presents and evaluates the mathematic model for a prebend blade for wind turbines at natural frequencies. The study was carried out by advanced beam model for ideal structure in a DU-97-W-300 cross sectional area. A Galerkin type of approach has been used to derive the equations and the analysis was performed involving a standard FEA code which involves PK method and double lattice method for calculating flutter solution and aerodynamic loads, respectively. The study is applied to structural stability, estimation of flutter region, nonlinear influence of blade length, and rotor velocity. The main conclusions from this paper are summarised as follows:

(1) The results reveal the significance of inducing prebending to improve the stability of the blade structures and hence, the flutter velocity has moved from $11 \mathrm{~m} / \mathrm{s}$ to $23 \mathrm{~m} / \mathrm{s}$

(2) The results also ensure that prebending in blades can be used significantly to modify its performances and structural stability without changing its aerodynamic properties

(3) New technique of obtaining damping curves with and without aerodynamic loads helps the designer to decide whether to modify the aerodynamic properties or structural properties for improved flutter limits

For future work, the methods and theories used here can estimate the flutter region but cannot provide any details about interaction of fluid and the dynamic behaviour of the structure beyond the flutter point to study requires a more comprehensive model. The recommendation for further studies is that a wind turbine blade can be manufactured in sections (split blades) and it can be easy for transportation as well as for installation. Thus, integration of joints and structural nodes should be evaluated for performance parameters. It can be extended to determine the impact of prebending of the blade on AEP (annual energy production) 
which can also be studied as the prebending will cause the turbine to have a higher AEP than rotors having straight blade due to the increase in the angle of attack along the length of the blade. And also, the impact of glue delamination of blade structure on flutter limits can be analysed [34].

\section{Abbreviations}

$\mathrm{A}$ and $\mathrm{B}$ :

C, D, and F:

E:

G:

$J:$

I:

$P:$

$X:$

$U:$

TE:

LE:

$w:$

$l:$

m:

$c:$

$q:$

$[\mathrm{K}]$ and $[\mathrm{M}]$ :

\section{[Q]:}

$k$ :

$n$ and $n^{1}$ :

$t$ :

j:

$I_{\theta}:$

$\mathrm{C}_{1}$ :

$\mathrm{C}_{2}$ :

$U_{\mathrm{c}}$ :

$Z_{\mathrm{G}}$ :

$C_{\mathrm{p}}$ :

$K_{\mathrm{L}}$ :

$E_{\mathrm{A}}$ :

$Y_{\mathrm{G}}$ :Shear centre distance in $Y$ direction $Y_{\theta}$ :

$F_{\mathrm{L}}:$
$F_{\mathrm{M}}:$
$x_{0}:$

$K_{T}:$

$A_{\mathrm{C}}$ :

$I_{\mathrm{A}}$ :Inertial axis DOF (degrees of freedom) angular deflection $\lambda$ : $\alpha$ :
Constant coefficients

Matrix variables

Young's modulus

Modulus of rigidity

Moment of inertia (polar)

Moment of inertia (Area) $L$

blade length

Load (wind velocity)

Deflection due to pitch

Air speed/wind velocity

Trailing edge

Leading edge

Linear deflection

Element length

Mass

Chord length

Coordinates in directions

Positive definite stiffness and mass symmetric matrix

Displacement matrix [P] load matrix

Stiffness

Number of modes

Time

Variable denoting the number

of the mode shape

Mass moment of inertia

Lift coefficient

Moment coefficient

Critical wind velocity

Shear centre distance in $Z$

direction

Centre of pressure

Bending stiffness

Elastic axis

Shear centre distance in $Y$ direction $Y_{\theta}$ Distance between mass centre and elastic axis at any section

Lift force

Moment

Distance between the aerodynamic centre and leading edge of the aerofoil

Torsional stiffness

Aerodynamic centre

Inertial axis DOF (degrees of

freedom) angular deflection $\lambda$ :

Eigenvalue

Real eigenvalue. $\omega:$

$\mathrm{U}:$

$\rho:$

$\varphi:$

\section{Data Availability}

The data used to support the findings of this study are included in the article.

\section{Conflicts of Interest}

The authors declare that they have no conflicts of interest.

\section{References}

[1] Y. Bazilevs, M.-C. Hsu, J. Kiendl, and D. J. Benson, "A computational procedure for prebending of wind turbine blades," International Journal for Numerical Methods in Engineering, vol. 89, no. 3, pp. 323-336, 2012.

[2] Y. C. Fung, An Introduction to the Theory of Aero Elasticity, John Wiley \& Sons, Hoboken, NJ, USA, 2008.

[3] V. V. Bolotin, Nonconservative Problems of the Theory of Elastic Stability, Pergamon Press, Oxford, UK, 1963.

[4] R. L. Bisplinghoff, H. Ashley, and R. L. Halfman, Aeroelasticity, Dover publications, Inc, Mineola, NY, USA, 2013.

[5] P. Pariya, Y. M. Sadeghi, and M. Lackner, "A parametric study of coupled-mode flutter for MW-size wind turbine blades," Wind Energy, vol. 19, no. 3, pp. 497-514, 2016.

[6] P. Pariya, L. Caracoglia, and M. Lackner, "Stochastic analysis of flow-induced dynamic instabilities of wind turbine blades," Journal of Wind Engineering and Industrial Aerodynamics, vol. 137, pp. 37-45, 2015.

[7] P. Pariya, L. Caracoglia, M. Lackner, and Y. M. Sadeghi, "Perturbation methods for the reliability analysis of windturbine blade failure due to flutter," Journal of Wind Engineering and Industrial Aerodynamics, vol. 156, pp. 159-171, 2016.

[8] M. H. Hansen, J. N. Sorensen, S. Voutsinas, N. Sorensen, and H. A. Madsen, "State of the art in wind turbine aerodynamics and aeroelasticity," Progress in Aerospace Sciences, vol. 42, no. 4, Article ID 42285, 2006.

[9] M. H. Hansen, "Aeroelastic stability analysis of wind turbines using an eigenvalue approach," Wind Energy, vol. 7, no. 2, pp. 133-143, 2004.

[10] M. H. Hansen, "Vibrations of a three-bladed wind turbine rotor due to classical flutter," in Proceedings of the Fortyth AIAA Aerospace Sciences Meeting and Exhibit, ASME Wind Energy Symposium, Reno,NV, USA, January 2002.

[11] E. H. Dowell, "Nonlinear oscillation of a fluttering plate," AIAA Journal, vol. 4, no. 7, 1996.

[12] E. H. Dowell and H. M. Voss, "Theoretical and experimental panel flutter study," AIAA Journal, vol. 3, no. 12, 1995.

[13] F. Chen, J. Liu, and Y. Chen, "Flutter analysis of an airfoil with nonlinear damping using equivalent linearization," Chinese Journal of Aeronautics, vol. 27, no. 1, pp. 59-64, 2014.

[14] W. Hao, B. Ma, and J. J. Ding, "The analysis of the flutter region of wind turbine blade," Applied Mechanics and Materials, Trans Tech Publications, vol. 423, , 2013.

[15] S. M. Larwood, C. P. Van Dam, and D. Schow, "Design studies of swept wind turbine blades," Renewable Energy, vol. 71, pp. 563-571, 2014. 
[16] S. M. Larwood, "Prediction and alleviation of flutter in swept wind turbine blades," in Proceedings of the 33rd wind energy symposium, AIAA Journal, vol. 1464, pp. 1-10, Kissimmee, FL, USA, January 2015.

[17] S. M. Larwood, "Flutter variations on a 5MW swept wind turbine blade," Journal Of Solar Energy Engineering: Including Wind Energy and Building Energy Conservation, vol. 138, no. 2, 2015.

[18] X. Guo, X. Fu, H. Shang, and J. Chen, "Integrated aerostructural optimization design of pre-bend wind turbine blades," Journal of Mechanical Science and Technology, vol. 30, no. 11, pp. 5103-5113, 2016.

[19] M. H. Hansen, "Aeroelastic properties of backward swept blades," in Proceedings of the 49th AIAA Aerospace Sciences Meeting Including the New Horizons Forum and Aerospace Exposition, Oriando, FL, USA, January 2011.

[20] C. pavese, T. Kim, and J. P. Murcia, "Design of a wind turbine swept blade through extensive load analysis," Renewable Energy, vol. 102, pp. 21-34, 2017.

[21] H. Salarieh, A. Alasty, and R. Vatankhah, "Vibration boundary control of micro-cantilever Timoshenko beam using piezoelectric actuators," Scientia, vol. 25, no. 2, pp. 711-720, 2018.

[22] S. S. Sahoo, C. K. Hirwani, and S. K. Panda, "Numerical analysis of vibration and transient behavior of laminated composite curved shallow shell structure: an experimental validation," Scientia, vol. 25, no. 4, pp. 2218-2232, 2018.

[23] M. H. Nahavandian and M. pourjafar, "Stability of thixotropic fluids in pipe flow," Scientia Iranica B, vol. 25, no. 2, pp. 790-798, 2018.

[24] J. Fakhraei, H. M. Khanlo, and M. Ghayour, "Chaotic behaviors of a ground vehicle oscillating system with passengers," Scientia Iranica, vol. 24, no. 3, pp. 1051-1068, 2017.

[25] D. W. Lobitz, "Parameter sensitivities affecting the flutter speed of a MW-sized blade," Journal of Solar Energy Engineering, vol. 127, no. 4, pp. 538-543, 2005.

[26] F. Meng, "Aero-elastic stability analysis for large-scale wind turbines," vol. 123, Aero-elastic stability analysis for largescale wind turbines, Delft, Netherlands, 2011, Doctoral thesis.

[27] B. C. Owens, B. R. Resor, D. Griffith, and J. E. Hurtado, "Impact of Modelling Approach on Flutter Predictions for Very Large Wind Turbine Blade Designs," Sandia National Laboratories (SNL-NM), Albuquerque, NM, USA, No. SAND-3108C. 1-11, 2013.

[28] J. Jonkman, S. Butterfield, W. S. Musial, and G. Scott, Definition of a 5-MW Reference Wind Turbine for Offshore System Development, National Renewable Energy Laboratory, Calorado, CO, USA, 2009.

[29] P. Shakya, M. R. Sunny, and D. K. Maiti, "A parametric study of flutter behavior of a composite wind turbine blade with bend-twist coupling," Composite Structures, vol. 207, pp. 764-775, 2018.

[30] R. Tamrakar and N. D. Mittal, "Campbell diagram analysis of open cracked rotor," Engineering Solid Mechanics, vol. 4, pp. 159-166, 2016.

[31] Y. Hua, N. Wang, and K. Zhao, "Simultaneous unknown input and state estimation for the linear system with a rankdeficient distribution matrix," Mathematical Problems In Engineering, vol. 2021, Article ID 6693690, 11 pages, 2021.

[32] K. Wang, C. Liu, J. Sun et al., "State of charge estimation of composite energy storage systems with supercapacitors and lithium batteries," Complexity, vol. 2021, Article ID 8816250, 15 pages, 2021.
[33] C. Liu, Q. Li, and K. Wang, "State-of-charge estimation and remaining useful life prediction of supercapacitors," Renewable And Sustainable Energy Reviews, vol. 150, Article ID 111408, 2021.

[34] H. S. S. Kumar and R. B. Anand, "Parametric study on impact of delamination on flutter velocity of wind turbine blade structure," in Proceedings of the AIP Conference Proceedings, vol. 2039, no. 1, April 2018, Article ID 20040. 